\title{
SENTINEL-4 combined optical assemblies
}

Simon Chelkowski, Steffen Kirschstein, Torsten Hertel, Ute Gawronski, Steffen Rienecker, et al.

Simon Chelkowski, Steffen Kirschstein, Torsten Hertel, Ute Gawronski, Steffen Rienecker, Eyk Gebhardt, "SENTINEL-4 combined optical assemblies," Proc. SPIE 11852, International Conference on Space Optics ICSO 2020, 1185233 (11 June 2021); doi: 10.1117/12.2599530

SPIE Event: International Conference on Space Optics - ICSO 2021, 2021, Online Only 


\section{International Conference on Space Optics-ICSO 2020}

Virtual Conference

30 March-2 April 2021

Edited by Bruno Cugny, Zoran Sodnik, and Nikos Karafolas
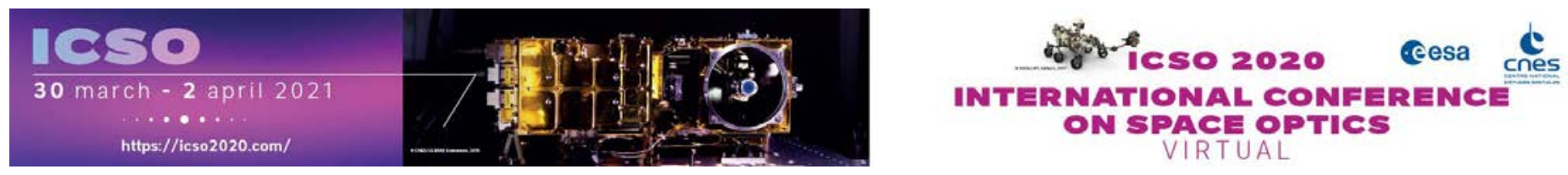

SENTINEL-4 combined optical assemblies

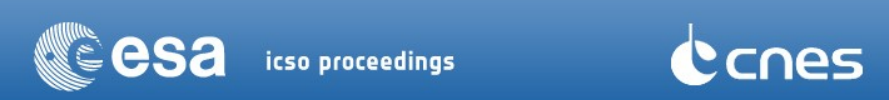

International Conference on Space Optics - ICSO 2020, edited by Bruno Cugny, Zoran Sodnik, Nikos Karafolas, Proc. of SPIE Vol. 11852, 1185233 - (c) 2021 ESA and CNES

CCC code: $0277-786 \mathrm{X} / 21 / \$ 21 \cdot$ doi: $10.1117 / 12.2599530$ 


\title{
Sentinel-4/UVN Combined Optical Assemblies
}

\author{
Simon Chelkowski*, Steffen Kirschstein, Torsten Hertel, Ute Gawronski, Steffen Rienecker, Eyk \\ Gebhardt \\ Jena-Optronik GmbH, Otto-Eppenstein-Strasse 3, 07745 Jena, Germany
}

\begin{abstract}
The ESA Sentinel-4 Mission is part of the European Commission Copernicus Programme for monitoring the Earth. It is going to provide free data on trace gas concentrations and aerosols in the atmosphere to support real time operational services of air-quality for Europe. The Sentinel-4/UVN Instrument will be placed in a geo-stationary orbit on board of the Meteosat Third Generation Sounder (MTG-S) satellite.

Jena-Optronik has been contracted to develop and build the core main optics of the Sentinel-4/Ultra-violet/Visible/NearInfrared (UVN) instrument, which comprises a telescope, a UV-VIS spectrometer and a NIR spectrometer. Due to its geo-stationary orbit and its compactness the photon flux seen by the instrument is low. Simultaneously the lens based optics of the instrument set new standards concerning performance. In consequence straylight levels within the instrument need to be reduced to the bare minimum including high quality polishing of the optics as well as manufacturing facilities as well as processes, which reduce the overall allowed contamination of the optical surfaces to be $<50 \mathrm{ppm}$ for particular and $<50 \mathrm{ng} / \mathrm{cm}^{2}$ molecular contamination.

Furthermore, the very demanding performance requirements led to an instrument design, which sets the demands on manufacturing and alignment quality to a new level. To realize the instruments performance over the complete specified thermal range Jena-Optronik developed a unique passive thermal focus compensation for the lens optics, which acts like a passive auto-focus system w.r.t. thermal changes. Moreover, we used precision lens mount manufacturing techniques to achieve the required lens positioning accuracy of less than $5 \mu \mathrm{m}$. The design of the instrument will be presented as well as the highlights from the assembly, integration and test campaign of the three core optics. All three PFMs, the telescope as well as the UV-VIS and the NIR spectrometers have been successfully delivered to Airbus Defence \& Space after ending their environmental test campaign successfully.
\end{abstract}

Keywords: Optical Instruments, Telescope, Spectrometer, Earth Observation, ESA Copernicus Programme, ESA Sentinel Missions, UV optic, Ultra-precision lens manufacturing

*simon.chelkowski@jena-optronik.de; phone +49 3641200 140; fax +49 3641200 220; www.jena-optronik.com

\section{INTRODUCTION}

The Sentinel-4 UVN Mission aims primarily at monitoring of the intra-day air quality evolution over Europe [1][2]. The Sentinel-4 mission consists of an Ultraviolet-Visible-Near-Infrared (UVN) light imaging spectrometer instrument [3][4], which will be placed in a geostationary orbit with the Meteosat Third Generation Sounder (MTG-S) satellite. The instrument itself is built by Airbus [5]. Its instantaneous field of view (iFoV) represents a vertical line with approximately the height of Europe. To produce an image of Europe the $\mathrm{iFoV}$ is scanned from east to west in hour [2]. In consequence several images can be taken during day time depending on the daily sun illumination varying with the seasons. This allows tracking the evolution of air pollution throughout the day.

The paper is structured into four sections. After a short introduction in Section 1 the main part (Section 2) of our paper focusses on the technical challenges and our achievements in this project. We will report on five technical challenges we have mastered and describe for each the motivation, our approach for the solution, the developed design and our achievement in a dedicated subsection (subsection 2.1 to 2.5). The paper ends with a conclusion in Section 3 and our acknowledgements in Section 4. 


\subsection{Contribution to Sentinel-4 UVN Instrument by Jena-Optronik GmbH}

The contributions from Jena-Optronik (JOP) focus on the main optics of the instrument except the scanner and the central structure. The Sentinel-4 UVN instrument is an imaging spectrometer with spectral ranges between 305-500nm as well as $750-775 \mathrm{~nm}$. The necessary optical assemblies to perform this task have been developed and manufactured by JOP, which in short comprise a high performance telescope including the spectral separation between the two main spectral bands as well as the two spectrometers and the two FPAs. A CAD representation of the instrument with its components is shown in Figure 1-1. The optical core components are highlighted in Figure 1-2 which show CAD models including the beam path. The light from earth in Figure 1-1 is entering from the top and is directed by the scan mirror into the Telescope Assembly (TA). This contains not only a telescope to image the light onto a slit, but also a beam splitter assembly which splits the light into it two wavelength ranges before an image is produced on the two slits inside the TA. The two spectrometers following the TA are the UV-VIS Spectrograph Assembly (USA) and the NIR Spectrograph Assembly (NSA). Each of the spectrometers separates the light into a spectrum, which is then imaged onto a detector inside the UV-VIS and NIR Focal Plane Assembly (UV-FPA and NIR-FPA).

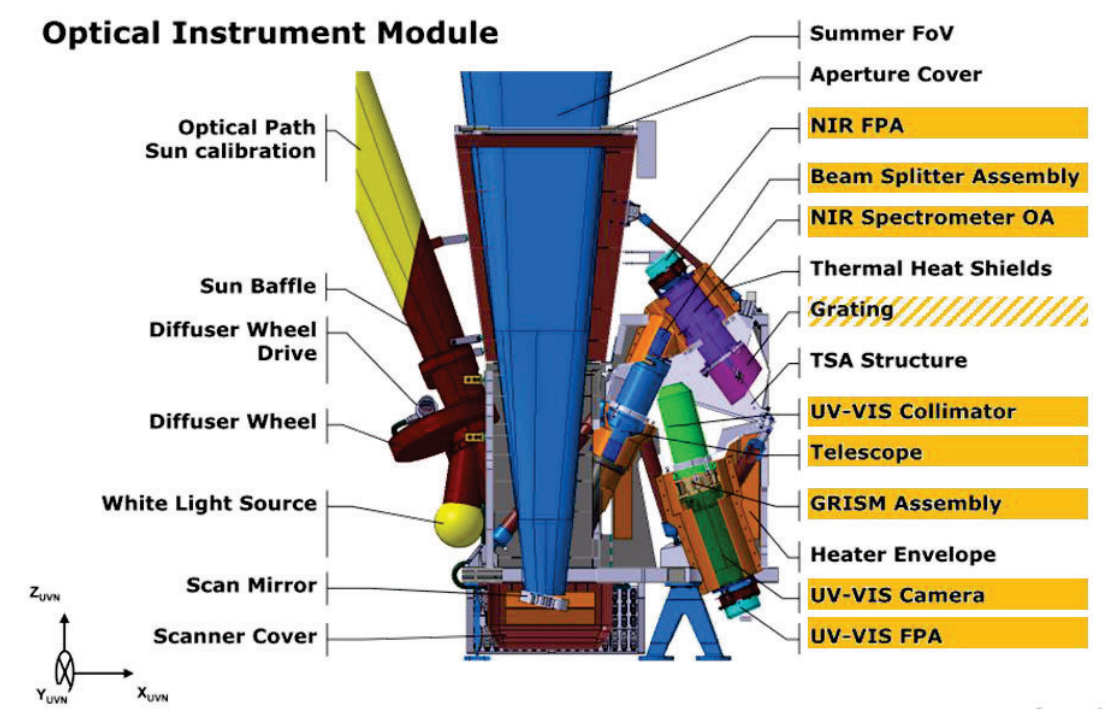

Figure 1-1: A CAD representation of the Sentinel-4 UVN Instrument. The components developed and manufactured by Jena-Optronik are indicated by orange boxes in the legend. The highlighted grating is embedded in the NIR Spectrometer Optical Assembly but is a Customer Furnished Item, which has been developed and manufactured by Fraunhofer Institute IOF from Jean, Germany. Image courtesy go to B. Veihelmann, ESA Sentinel 4 Lead Scientist and Airbus Ottobrunn 

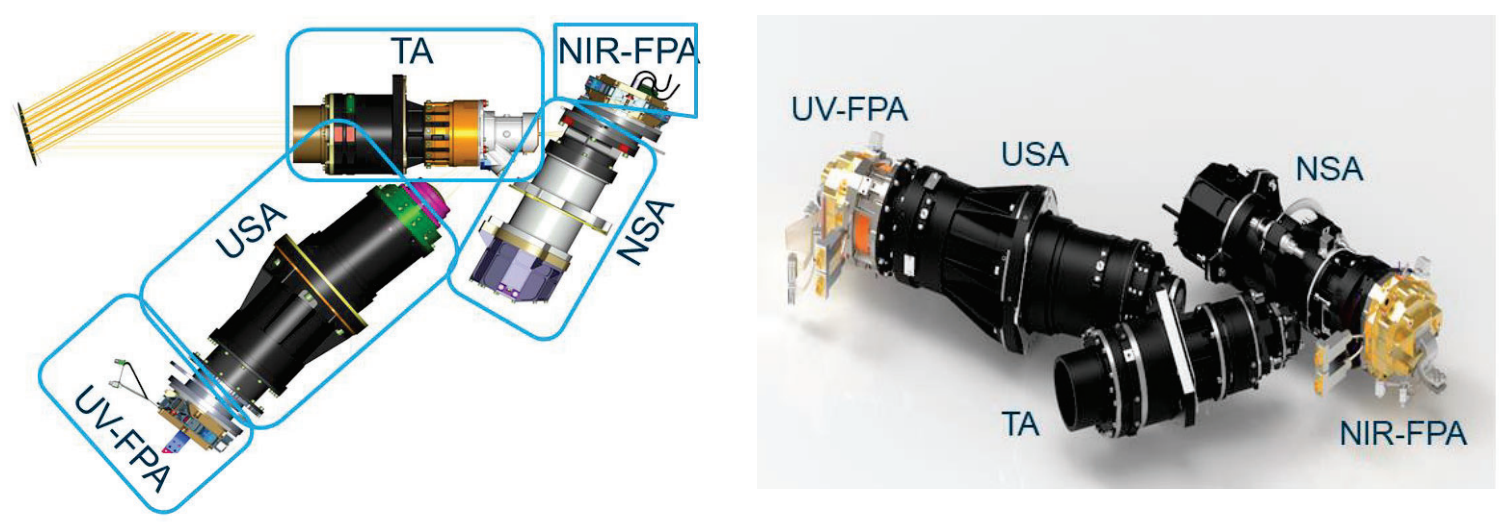

Figure 1-2: CAD representations of the optical core modules developed and manufactured by Jena-Optronik. Left: CAD including the optical beam path (orange lines). The light from earth is entering from the top and is directed by the scan mirror into the Telescope Assembly (TA). This contains not only a telescope to image the light onto a slit, but also a beam splitter assembly which splits the light into it two wavelength ranges before an image is produced on the two slits inside the TA. The two spectrometers following the TA are the UV-VIS Spectrograph Assembly (USA) and the NIR Spectrograph Assembly (NSA). Each of the spectrometers separates the light into a spectrum, which is then imaged onto an detector inside the UV-VIS and NIR Focal Plane Assembly (UV-FPA and NIR-FPA). Right: high quality CAD rendering of the three combined optical assemblies and the two focal plane assemblies.

\section{TECHNICAL CHALLENGES \& ACHIEVEMENTS}

This paper focuses on several technical challenges, which are a consequence of long refractive imaging chain in the UVVIS to NIR spectral range to be built as close as possible to the performance of the nominal design. The main optical assemblies, the Telescope Assembly (TA), the UV-VIS Spectrograph Assembly (USA) and the NIR Spectrograph Assembly (NSA) are summarized in their fundamental architecture in Table 1. The Focal Plane Assembly also manufactured by JOP is not in focus of this paper and therefore not shown in detail.

Table 1: The main optical architecture parameters of SENTINEL-4/UVN Combined Optical Assemblies

\begin{tabular}{|c|c|c|c|}
\hline & Telescope Assembly & $\begin{array}{l}\text { UV-VIS Spectrograph } \\
\text { Assembly (USA) }\end{array}$ & $\begin{array}{l}\text { NIR Spectrograph } \\
\text { Assembly (NSA) }\end{array}$ \\
\hline $\begin{array}{l}\text { Comprised } \\
\text { sub-assemblies }\end{array}$ & $\begin{array}{l}\text { Telescope optical assembly } \\
\text { (TOA) \& } \\
\text { Beamsplitter Assembly } \\
\text { (BSA) }\end{array}$ & $\begin{array}{l}\text { UV-VIS Spectrograph } \\
\text { optical Assembly (UV- } \\
\text { SOA) made out of } \\
\text { Collimator optic and } \\
\text { Camera optic \& } \\
\text { GRISM }\end{array}$ & $\begin{array}{l}\text { NIR Spectrograph Optical } \\
\text { Assembly (NI-SOA) \& } \\
\text { Grating Assembly (GRA) } \\
\text { CFI by Airbus }\end{array}$ \\
\hline $\begin{array}{l}\text { Wavelength } \\
\text { range }\end{array}$ & $\begin{array}{l}\text { UV-VIS: } 305 \mathrm{~nm}-500 \mathrm{~nm} \\
\& \text { NIR: } 750-775 \mathrm{~nm}\end{array}$ & UV-VIS: $305 \mathrm{~nm}-500 \mathrm{~nm}$ & NIR: $750-775 \mathrm{~nm}$ \\
\hline $\begin{array}{l}\text { \# of optical } \\
\text { elements }\end{array}$ & $\begin{array}{l}6 \text { lenses, } 1 \text { beam splitter } \& 2 \\
\text { slits }\end{array}$ & 10 lenses, 1 GRISM & $\begin{array}{l}3 \text { lenses, } 1 \text { fold mirror, } 1 \\
\text { grating }\end{array}$ \\
\hline
\end{tabular}




\begin{tabular}{|l|l|l|l|}
\hline $\begin{array}{l}\text { Optical } \\
\text { Materials used }\end{array}$ & $\mathrm{SiO}$, CaF2 & $\mathrm{SiO}$, CaF2 & LAK9, SF6, SiO2 \\
\hline Imaging type & Infinity to focal plane & $1: 1$ & $1: 1$ \\
\hline Specialties & $\begin{array}{l}\text { High Transmission in full } \\
\text { wavelength range, Precision } \\
\text { positioning of slits and } \\
\text { corresponding stability }\end{array}$ & $\begin{array}{l}\text { High spectral separation } \\
\text { acquired by GRISM } \\
\text { element } \rightarrow \text { separate } \\
\text { collimator \& camera optics }\end{array}$ & $\begin{array}{l}\text { Optical system is used in } \\
\text { double path to act as } \\
\text { collimator and camera at the } \\
\text { same time }\end{array}$ \\
\hline
\end{tabular}

The broad spectral range from $305 \mathrm{~nm}$ up to $775 \mathrm{~nm}$ limits the TA and USA optics to finally two diffractive materials (CaF2 and Fused Silica). The design is optimized to reduce the chromatic aberration over the wide spectral range, which results in a tremendous thermal sensitivity. To achieve a high precision imaging system, the high quality lenses needs to be mounted stress reduced and highly centered to achieve a highly stable focus position. The calibration stability of the overall systems has determined a high opto-mechanical stability in size of sub-pixels $(<30 \mu \mathrm{m})$ under space-optics typical loads like radiation, vacuum and gravity transitions, temperature as well as vibration and shock loads.

JOP and the suppliers involved in the realization had to put tremendous amount of effort to realize the Combined Optical Assemblies (COAs) and to achieve the project goals. In the coming subsections key developments will be presented starting with the area of conflict (motivation), the resulting approach to solve the issue, the final design and the results of the verification. For this paper we selected the key developments given in Table 2.

Table 2: The main key developments to be addressed in the next chapters

\begin{tabular}{|l|l|}
\hline Key Developments & Issues addressed \\
\hline Passive athermalisation & Thermal sensitivity \\
\hline Lens Gluing & Structural integrity and stress free \\
\hline Lens Centering & High end optical quality \\
\hline Clamping & Position stability \\
\hline Stray Light & Spectral crosstalk, Signal-to Noise Ratio \\
\hline
\end{tabular}

\subsection{Passive Athermalization}

\subsubsection{Motivation}

The UV Optics for TA and USA consist of CaF2 and SIO2 Doublets needed for a proper chromatic correction. These on the other hand induce a high thermal sensitivity of the image position. For the telescope, there are three CaF2 and SIO2 Doublets in place. The doublet components have very different CTEs (CaF2 19ppm K $\mathrm{K}^{-1}$ and SIO2 $\left.0.5 \mathrm{ppmK} \mathrm{m}^{-1}\right)$ which cause additional trouble in the mounting of the lenses. The thermal sensitivity of the image positions results in a defocus of $\sim 49 \mu \mathrm{m} / \mathrm{K}$. In the beginning of the project, the operating thermal range was defined by $17^{\circ} \mathrm{C}$ toll $23^{\circ} \mathrm{C}$. If no compensation is used the useful range of operation shrinks to $19.8^{\circ} \mathrm{C}-20.3^{\circ} \mathrm{C}$. This was not acceptable. All classical approaches to compensate this amount by proper material combination between optics and FPA (including Slits) had failed.

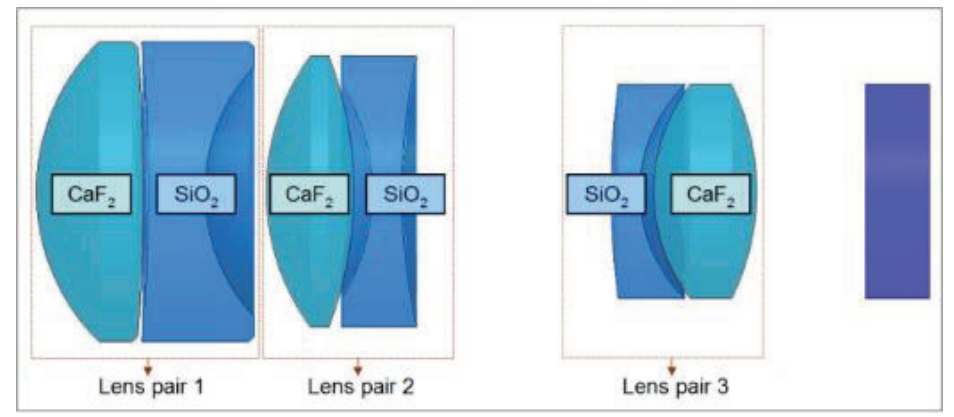

Figure 2-1: Telescope design sketch with three doublets of $\mathrm{CaF} 2$ and $\mathrm{SiO} 2$ 


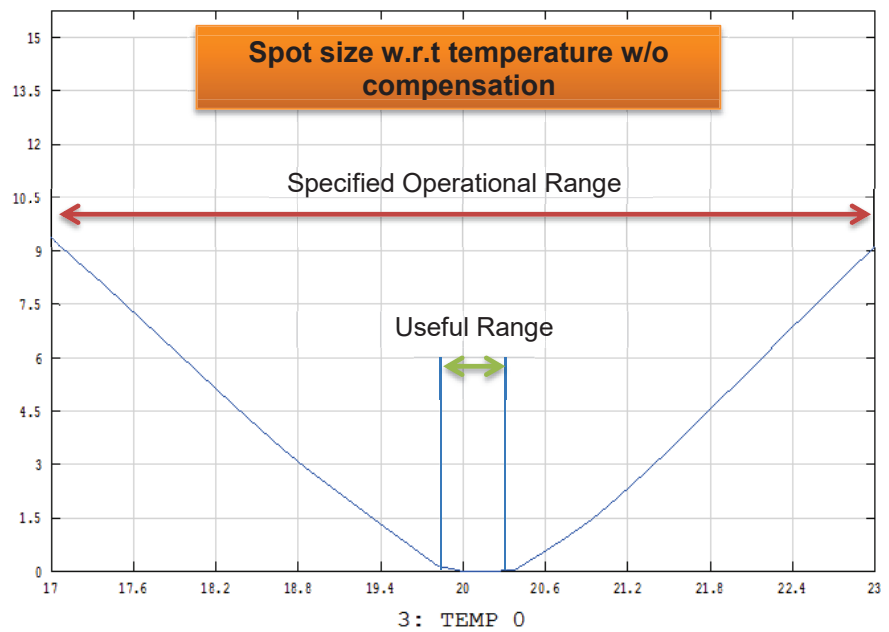

Figure 2-2: Thermal sensitivity of the telescope (Change of Maximum RMS spot size in the focal plan)

\subsubsection{Approach of Solution}

The sensitivity analysis showed that the inter-lens distance between the doublet partners shifts the image plane quite strongly too defining on one hand a high position stability requirement but gives on the other hand the opportunity to correct the image position w.r.t thermal shifts. This results finally in the approach that sufficient thermal focus compensation can be applied by shifting the inter-lens distances between the optical active doublets by means of defined small additional movement (see Figure 2-3). This additional movement up to $4 \mu \mathrm{m} / \mathrm{K}$ per doublet should be realized in a passive mode, without the use of an active actuator. The lens movement was realized by a passive, highly optimized lever mechanism, which was implemented into the lens mount of the $\mathrm{SiO} 2$ lenses by transforming a radial movement of the aluminum tube and mount rings in an axial movement of the $\mathrm{SiO} 2$ lens mounted in Invar.

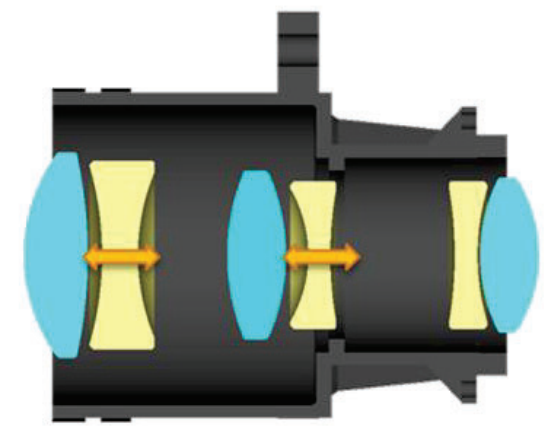

Figure 2-3: Shifting of inter-lens distance at Telescope (TOA) to reduce the defocus due to high thermal sensitivity of the doublet

The rationale for choosing this lens mount was also that we already had to design this lens mount with flexible hinges to allow a free differential expansion due to the strong different coefficient of thermal expansion (CTE) mismatch between lens mount material Invar for $\mathrm{SiO} 2$ lenses and lens tube and $\mathrm{CaF} 2$ mount material A14032 (Al alloy with $\sim 19 \mathrm{ppm} \mathrm{K}^{-1}$ ). These materials were chosen to reduce the stress in the lens and its mount. Taking advantage of the high CTE of Al4032, it also reduces the additional movement and therefore the thermal defocus. It emerged that the hinges containing the needed lever-like mechanism that allows the shifting of the inter-lens distance. Hence, our mount design provides a purely mechanical, non-electrical and therefore compact passive athermalization mechanism. The working principle is shown schematically in Figure 2-4. 


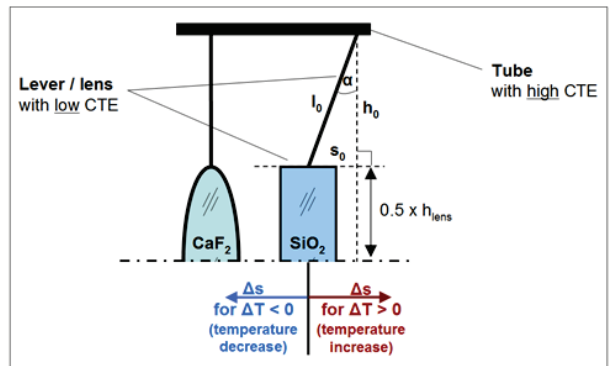

Figure 2-4: Schematic diagram of the athermalization mechanism based on different thermal expansion behavior. The tube represents the outer ring of the lens mount. $h_{0}$ is the initial distance between lens and tube. hlens is the height of the lens. $\alpha$ is $90^{\circ}$ minus the angle between lever and tube. $1_{0}$ is the initial length of the lever (results from $h_{0}, \alpha$ and relations in right-angled triangle). so results from $\mathrm{l}_{0}, \mathrm{~h}_{0}$ and $\alpha$.

When the temperature increases, the outer lens ring expands by a certain amount due to the high CTE of the material (A14032). The SiO2 lens with the Invar lens ring and the lever expand hardly due to low CTE (Invar, titanium). These expansion differences lead to a movement of the $\mathrm{SiO} 2$ lens along optical axis, provided that the lever is connected to the outer lens ring by several flexures hinges designed in a lever-like mechanism adjusted by a certain angle.

\subsubsection{Design}

The athermalization mechanism, which provides the lens movement, is based on different thermal expansion behavior of materials. Thereby, the moved lens (SiO2) is mounted in an inner ring made of Invar and connected to an outer lens ring made of Al4032 via an additional lever mount. This lever mount contains several flexure hinges arranged in a ring shape and uses also a very low CTE value like the inner ring through the choice of the material titanium.
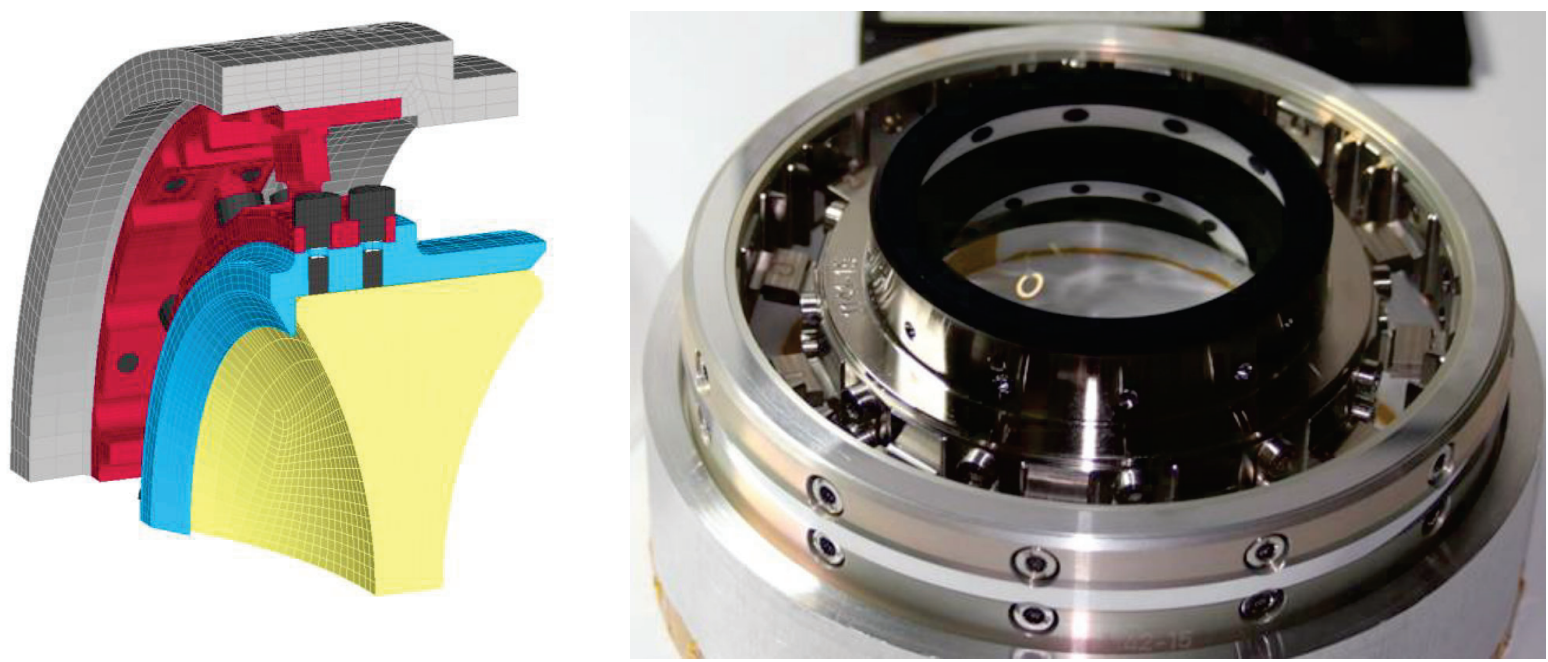

Figure 2-5:Athermalization mechanism. Left: Finite element model (FEM) containing inner mount (light blue), outer mount (grey) and the lever mount with several flexure hinges (red). Right: Telescope lens TES4 in its lever mount

Due to the fact that more than one of the single lens mounts with a Fused Silica lens have these kind of lever, the required total movement of each lever could be reduced. This was worthwhile regarding the stress in the flexure hinges produced by this movement, since they are strong pre-stressed due to assembling and therefore closing of clearance gaps of the lens mount system which includes outer ring, inner ring and lever mount. This clearly shows the challenge of this compact passive athermalization mechanism. The stability requirement (refer to chapter 2.1.2) allows only an axial shift less than $3 \mu \mathrm{m}$ which leads to the fact, that any risk of plastic deformation, which could lead to hysteresis effects, must be prevented. 
All spacecraft structures undergo various static, dynamic and thermal environmental loads. Therefore, a dedicated qualification campaign on separate models was done to prove that the mechanism fulfills performance and stability requirements after exposure to base shake qualification random vibration level (8.34 $\left.\mathrm{g}_{\mathrm{rms}}\right)$ and non-operational thermal cycling loads $\left(+45^{\circ} \mathrm{C} / 0^{\circ} \mathrm{C}\right)$. For this campaign a flight representative lens mount assembly of the Telescope TES4 lens was built with the difference of the $\mathrm{SiO}_{2}$ lens plate instead of using a real lens. This assembly was named risk mitigation model (RMM). An overview of the test setups to qualify the design and some values measured thereby are given in Figure 2-6.
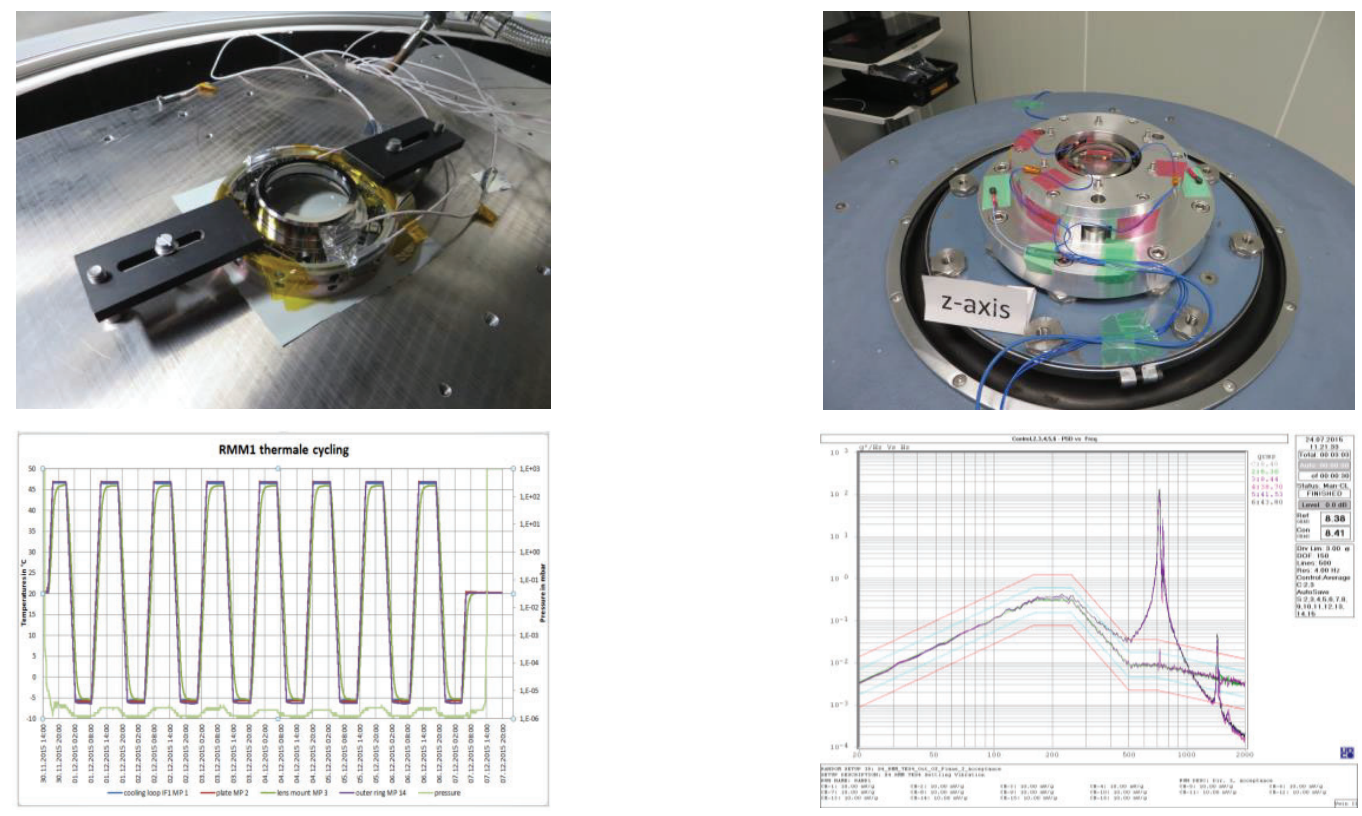

Figure 2-6: Left: Test setup for Thermal Vacuum (TV) cycling test of RMM and temperature profiles recorded at different positions of the set-up. Left: Test setup for random vibration test of RMM and recorded PSD of different accelerometers

In order to evaluate the stability of the performance of the lever mechanism, the lens shift measurement of the $\mathrm{SiO} 2$ plate was performed as initial lens shift measurement after completion of manufacturing and integration campaign and as final lens shift measurement after random vibration and thermal loads had been applied.

To achieve this lens shift characterization of the lever mechanism, the thermal shift of the plate with respect to its mount had to be determined. Therefore, a measurement of the varying position of the $\mathrm{SiO}_{2}$ plate and its mount during the realization of a specified temperature regime was performed by the use of three chromatic confocal sensors. The test setup for the lens shift measurement is shown in Figure 2-7.

The lens shift measurements were compared with structural analysis results using a very detailed finite element model (FEM) illustrated in Figure 2-5 (left hand side). This model was created to investigate in detail the effects on the lens movement (shift) caused by the design of the lever assembly. For that reason, the bolt preload, contact and clearance were modeled and simulated. One can see that the predicted values with a determined shift of $3.7 \mu \mathrm{m} / \mathrm{K}$ correlate very well with the real lens shift measurement of the RMM of the initial test with $3.6 \mu \mathrm{m} / \mathrm{K}$ shift (see Figure 2-7). During the final lens shift measurement after exposure of random and thermal loads a shift of $3.8 \mu \mathrm{m} / \mathrm{K}$ was determined. 


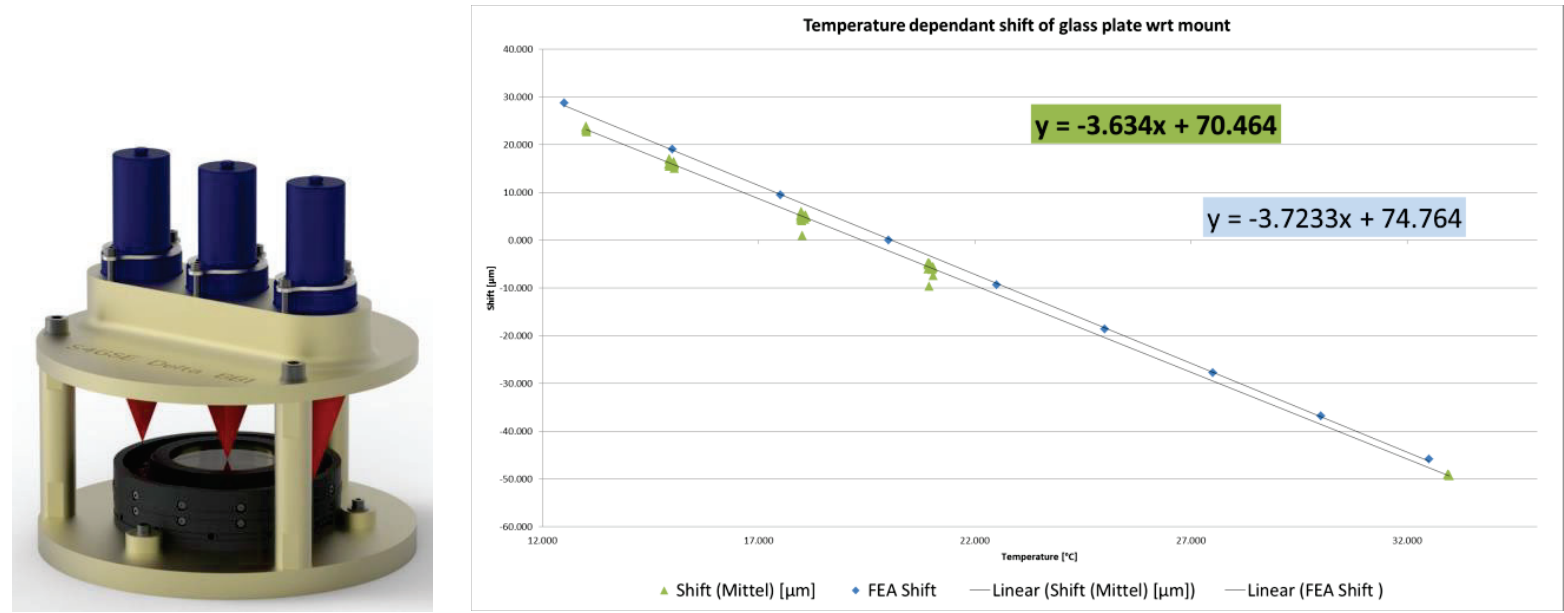

Figure 2-7: Left: Test setup for the lens shift measurement; Right: Comparison of temperature dependent shift of RMM $\mathrm{SiO} 2$ plate with respect to its mount of the initial test (green triangles) to the predicted values using a very detailed FEM (blue circles)

In summary, the performance of the design of the lever mechanism between the $\mathrm{SiO} 2$ plate and its mount was demonstrated. Furthermore, taking into account the uncertainty of the measurement method itself (in the range of $\pm 5 \%$ ), the required stability of the athermalization mechanism with respect to qualification random vibration and thermal loads was verified.

Table 3: Summary of the lever mechanism performance evaluation. The measurements performed before and after random and thermal loads on RMM are compared to the FEM analysis

\subsubsection{Achievement}

\begin{tabular}{|l|l|}
\hline & Athermalisation shift $[\boldsymbol{\mu} \mathbf{m} / \mathbf{K}]$ \\
\hline FEM analysis & $3.7(2)$ \\
\hline Initial test RMM & $3.6(3)$ \\
\hline Final test RMM & $3.8(4)$ \\
\hline
\end{tabular}

After successful subsystem verification using the RMM, all flight model lever mounts were manufactured and tested. The deviation between design prediction and test were less than $0.3 \mu \mathrm{m} / \mathrm{K}$. After integration by means of diamond turning centration, the lens optical performance over temperature was verified by means of through focus measurements of at different Test temperatures: $18.5^{\circ} \mathrm{C}, 20.0^{\circ} \mathrm{C}, 21.5^{\circ} \mathrm{C}$, which were the reduced specified temperature ranges at this state of the project.

The through focus measurement determined over a field of $\pm 2^{\circ}$ by a collimator setup in front of a high precision 2 -axis turn table as shown in Figure 2-8. The through focus measurement -typical result in Figure 2-8- has shown excellent image stability of $15 \mu \mathrm{m}$ in UV-VIS and of $\sim 30 \mu \mathrm{m}$ at NIR Image, see Table 4 and Figure 2-12. Just to remember the expected shift without passive athermalization over $3 \mathrm{~K}$ would have been approximately $150 \mu \mathrm{m}$, whereas the levers could reduce the image shift to about $1 / 10$ to $2 / 10$. 

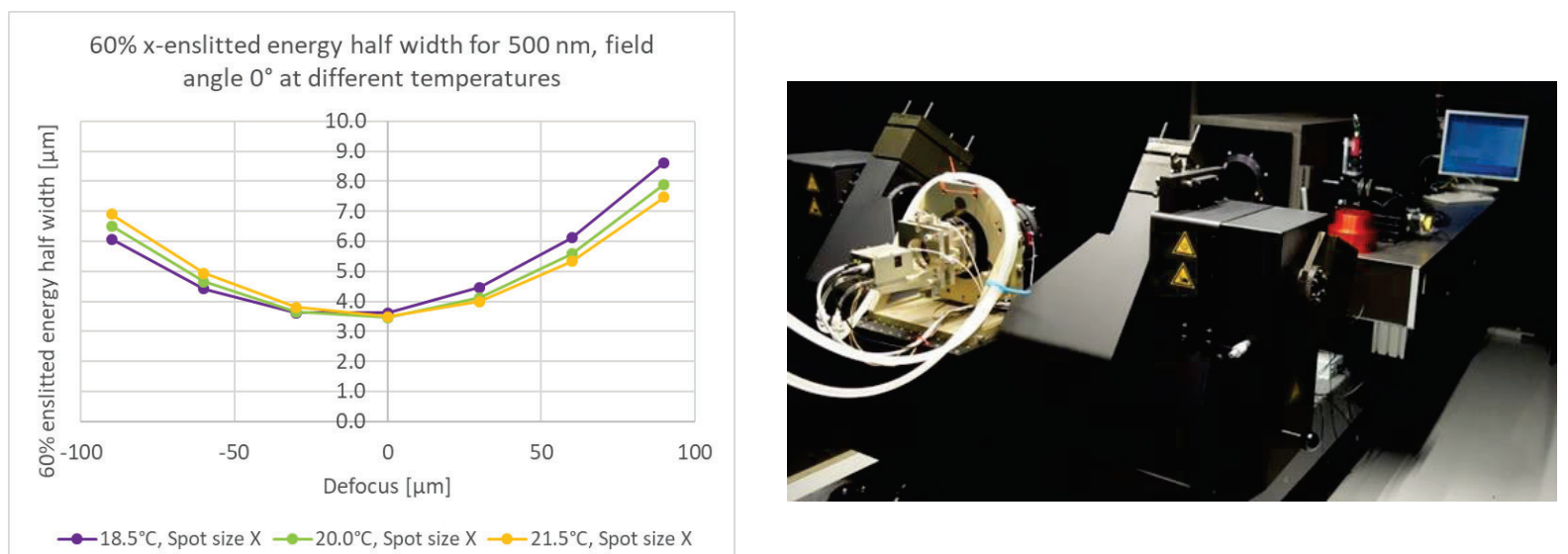

Figure 2-8: Left: Through focus measurement of spot size (here x-enslitted energy) Right: OGSE to determine through focus measurement as function of temperature

Table 4: Measured image plane shift for the telescope

\begin{tabular}{|c|c|c|}
\hline Test temperature $\left[{ }^{\circ} \mathbf{C}\right]$ & $\begin{array}{c}\text { Shift of UV-VIS image } \\
\text { plane }[\boldsymbol{\mu m}]\end{array}$ & $\begin{array}{c}\text { Shift of NIR image plane } \\
{[\boldsymbol{\mu m}]}\end{array}$ \\
\hline 18.5 & -7.5 & -19.5 \\
\hline 20.0 & 0.0 & 0.0 \\
\hline 21.5 & 8.1 & 15.9 \\
\hline
\end{tabular}

\subsection{Lens Gluing}

\subsubsection{Motivation}

The optical performance requirements demand an almost nominal image quality. Therefore all elements of lens manufacturing are optimized, including the reduction of stress induced lens deformation. In consequence only very minor shape deviations of optical elements are allowed, tight manufacturing tolerances on lenses were defined and procured but also the mounting technology of optical elements may not deteriorate the optical performance.

The approach JOP chose was to use mounting material almost with the same CTE as the refractive material and a glue connection. No standard approaches of optical adhesives could be used, because any glue based mounting technology requires bake-out efficiency to reduce molecular contamination to an almost completely negligible level. This is especially true for the UV wavelength range.

\subsubsection{Solution}

We came up with a soft mounting technology based on a self-blackened Hysol EA9361 adhesive, which acts as cushion but requires a special curing regime.

Two solutions have been developed. One uses individual glue pads on lens rim whereas for the brittle CaF2 we developed a solution based on connected pads forming a glue ring surrounding the lens rim. The glue pads were applied under volume dosage and are visual controlled during injection. The glue pad diameter variation achieved is better than $\pm 0,5 \mathrm{~mm}$.

Lens-assembly level bake-out at $60^{\circ} \mathrm{C}$ slightly above glass temperature were performed with a duration of about $120 \mathrm{~h}$. 


\subsubsection{Achievement}

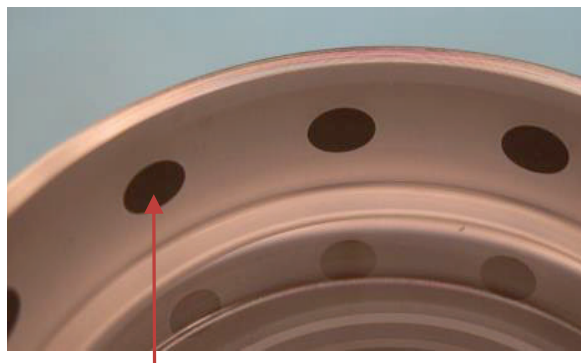

Glue pad

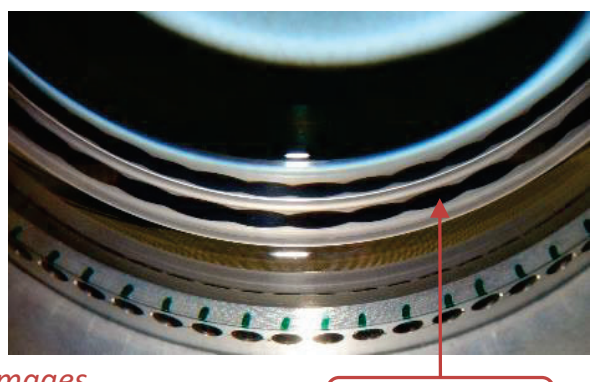

Glue line

Figure 2-9: Both used types of glue connection; Left: Single defined glue pads and Right: Glue line based joined pads

Both gluing solutions ran through a full qualification campaign with the individual steps performed as summarized in Table 5. These full qualification campaigns (Table 5) on various models in advance to the manufacturing of the PFMs were done including polarization and wave-front (interferometric lens surface) measurements (WFE) to check for deviations. The stress-induced birefringence was small on the single pad glue joints, but the effects on the lens surface were always negligible and in the range of measurement accuracy (repeatability), see Figure 2-10. In Figure 2-11, you can see the measured wave front error data for a fused silica lens, which shows changes in the wave front irregularity of less than 0.4 fringes.

Table 5: Qualification test program for mounted lenses with glue joints

\begin{tabular}{|c|c|}
\hline Step & Test Steps \\
\hline 1 & Polarization + WFE \\
\hline 2 & Gluing + Curing \\
\hline 3 & Polarization + WFE \\
\hline 4 & Bake-Out Assembly [60 $\left.60^{\circ} \mathrm{C}, 500 \mathrm{~h}\right]$ \\
\hline 5 & Polarization + WFE \\
\hline 6 & Humidity \\
\hline 7 & Proof Test (up to $18 \mathrm{~K} / \mathrm{h})$ \& Bake \\
\hline 8 & out [60 $\left.{ }^{\circ} \mathrm{C}, 24 \mathrm{~h}\right]$ \\
\hline 9 & Vibration \\
\hline
\end{tabular}
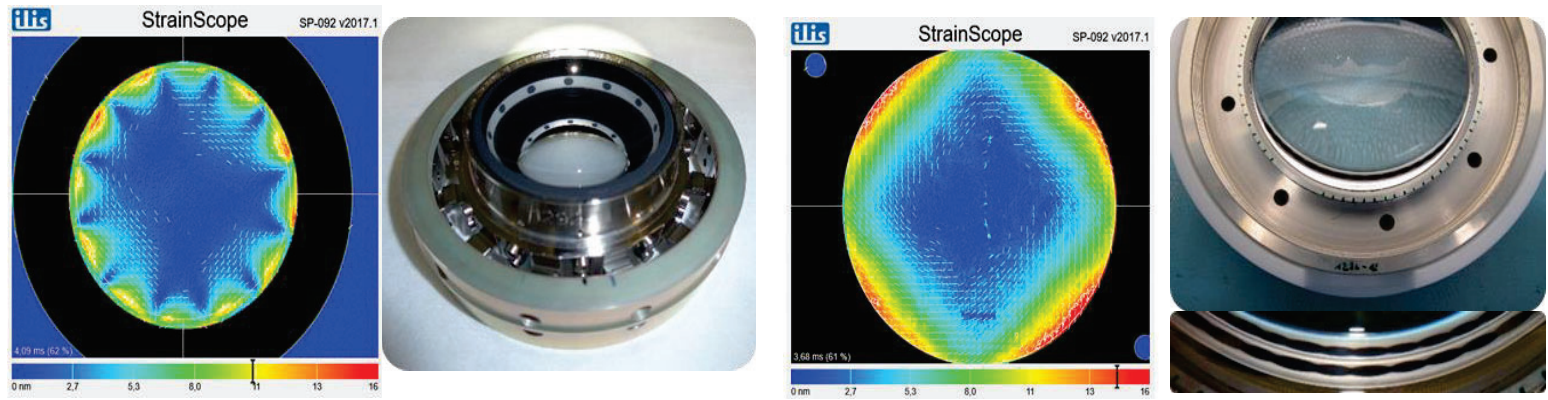

Figure 2-10: Verification of stress-induced birefringence by means of polarization measurements (Left: Single pads glue joint on $\mathrm{SiO} 2$ lens. Birefringence is less than $10 \mathrm{~nm} / \mathrm{cm}$ and mostly outside the optical free. Right: Polarization measurements on $\mathrm{CaF} 2$ lens (glue ring). Trefoil structure is caused by lens curvature itself. No birefringence resolved) 

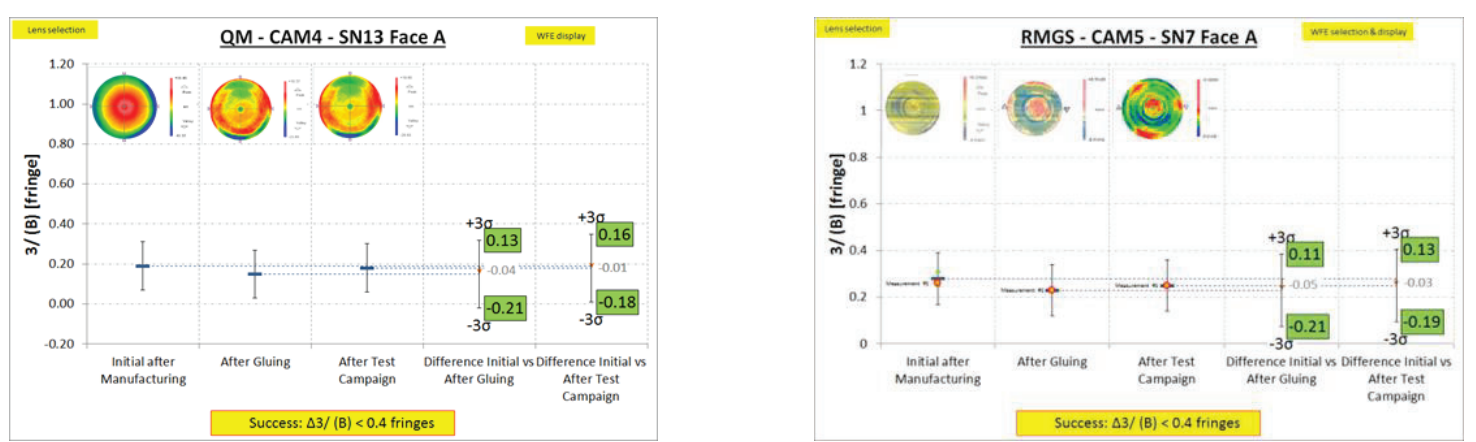

Figure 2-11: Verification of stress-induced lens deformation by wave-front (interferometric lens surface) measurements

(Left: Single pads glue joint on $\mathrm{SiO} 2$ lens. Right: $\mathrm{CaF} 2$ lens (glue ring). Variation of Surface shape Irregularity variation was in the size of measurement accuracies.

\subsubsection{Achievement}

The final verification of the successful development was done in the frame of the first flight model test program. The telescope spot size performance verification results had finally proven that the goal of the program was achieved and all spot sizes are most likely in the range of the requirement, see Figure 2-12. Hence, we had successfully demonstrated a compliant optical performance after the verification campaign ended.

\begin{tabular}{|c|c|c|c|c|c|c|c|}
\hline \multirow{3}{*}{ 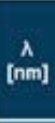 } & \multirow{3}{*}{$\begin{array}{c}\text { Field } \\
\text { angle } \\
\text { [] }\end{array}$} & \multicolumn{2}{|c|}{$18.5^{\circ} \mathrm{C}$} & \multicolumn{2}{|c|}{$20.0^{\circ} \mathrm{C}$} & \multicolumn{2}{|c|}{$21.6^{\circ} \mathrm{C}$} \\
\hline & & $\begin{array}{c}\text { Spotsize } \\
\text { X fuml }\end{array}$ & $\begin{array}{c}\text { Spotsize } \\
\text { Y fum] }\end{array}$ & $\begin{array}{c}\text { Spotsize } \\
\text { X [um] }\end{array}$ & $\begin{array}{c}\text { Spotsize } \\
\text { Y fuml }\end{array}$ & $\begin{array}{c}\text { Spotsize } \\
\text { X fuml }\end{array}$ & $\begin{array}{c}\text { Spotsize } \\
\text { Y fum] }\end{array}$ \\
\hline & & $\leq 6.2$ & $\leq 4.4$ & $\leq 6.2$ & $\leq 4.4$ & $\leq 6.2$ & $\leq 4.4$ \\
\hline \multirow{9}{*}{466} & -2.0 & 5.1 & 29 & 4.5 & 2.9 & 4.1 & 3.3 \\
\hline & -1.5 & 3.9 & 3.2 & 3.6 & 3.2 & 30 & 30 \\
\hline & -1.0 & 3.5 & 32 & 27 & 2.8 & 2.9 & 3.0 \\
\hline & -0.5 & 3.1 & 3.0 & 3.0 & 30 & 3.4 & 3.4 \\
\hline & 0.0 & 29 & 29 & 3.6 & 3.5 & 3.5 & 3.5 \\
\hline & 0.5 & 3.3 & 3.1 & 3.2 & 3.3 & 28 & 29 \\
\hline & 10 & 33 & 3.1 & 3.1 & 3.1 & 30 & 3.2 \\
\hline & 1.5 & 39 & 3.0 & 3.4 & 29 & 3.1 & 3.0 \\
\hline & 2.0 & 5.2 & 29 & 47 & 3.2 & 4.4 & 32 \\
\hline
\end{tabular}

Figure 2-12: Spot size of the Telescope PFM over different field angles at $466 \mathrm{~nm}$ and the whole temperature range

\subsection{Lens Centering (xyz-position \& tilt control)}

\subsubsection{Motivation}

The very demanding requirements shown in Table 6 as residuals between end of life performance and design performance demand a high position and tilt control of each optical element. Especially the distortion maximum for all the main components like Telescope, UV-VIS Spectrometer and NIR spectrometer are in the range of $1.4 \mu \mathrm{m}$ till $2.1 \mu \mathrm{m}$. For such small values a proper budgeting demands a single lens positioning in the range of decenter $( \pm \sigma$ between $<2.1 \mu \mathrm{m}$, cutoff $4.2 \mu \mathrm{m})$ and tilt $( \pm \sigma$ between $<3.1 \operatorname{arcsec}$, cutoff $6.2 \mathrm{arcsec})$. 
Table 6: Residuals between end of life performance and design performance.

\begin{tabular}{|c|c|c|c|c|}
\hline & \multicolumn{3}{|c|}{ Nominal Residual Margin } & \multirow[b]{2}{*}{ Unit } \\
\hline Requirement & TELESCOPE & $\begin{array}{c}\text { UV-VIS } \\
\text { Spectrometer }\end{array}$ & $\begin{array}{c}\text { NIR } \\
\text { Spectrometer }\end{array}$ & \\
\hline \multicolumn{5}{|l|}{ Focal Length /Magnification Shift } \\
\hline in Slit direction & $\mathbf{0 , 1}$ & $1,8 \mathrm{E}-4$ & $1,5 \mathrm{E}-5$ & $\mathrm{~mm} / \mathrm{a} . \mathrm{u}$. \\
\hline \multicolumn{5}{|l|}{ Distortion } \\
\hline NIR Distortion (MAX over fields and wavelengths) & 2,1 & $\mathbf{N A}$ & 1,9 & $\mu \mathrm{m}$ \\
\hline UVVIS Distortion (MAX over fields and wavelengths) & 2,3 & 1,4 & NA & $\mu \mathrm{m}$ \\
\hline Inter-band Distortion (MAX) & 1,0 & NA & NA & $\mu \mathrm{m}$ \\
\hline \multicolumn{5}{|l|}{ Co-Registration } \\
\hline Intra-band Co-Registration (MAX of all fields) & $\mathbf{0 , 3}$ & $\mathbf{N A}$ & NA & $\mu \mathrm{m}$ \\
\hline Inter-band Co-Registration (MAX of all fields) & 0,5 & NA & NA & $\mu \mathrm{m}$ \\
\hline \multicolumn{5}{|l|}{ Spot size } \\
\hline $\begin{array}{l}\text { Minimum Enslitted Energy } 60 \% \\
\text { (MAX over field and wavelengths)) }\end{array}$ & 2,8 & 3,1 & 4,0 & $\mu \mathrm{m}$ \\
\hline
\end{tabular}

\subsubsection{Approach of Solution and Design}

To avoid stress on singlets for Telescope and UV-VIS spectrometer the lens barrel is made of an Aluminum alloy (AL4032) close to the CTE of CaF2 ( 19ppm). Using aluminum as well as centering material produced a risk of sticking of the single lens assemblies in the lens tube during the joining process. To avoid sticking of singlets in the joining process a highly smoothed surface quality - metal mirror quality - was achieved using Ni plated as finishing material.
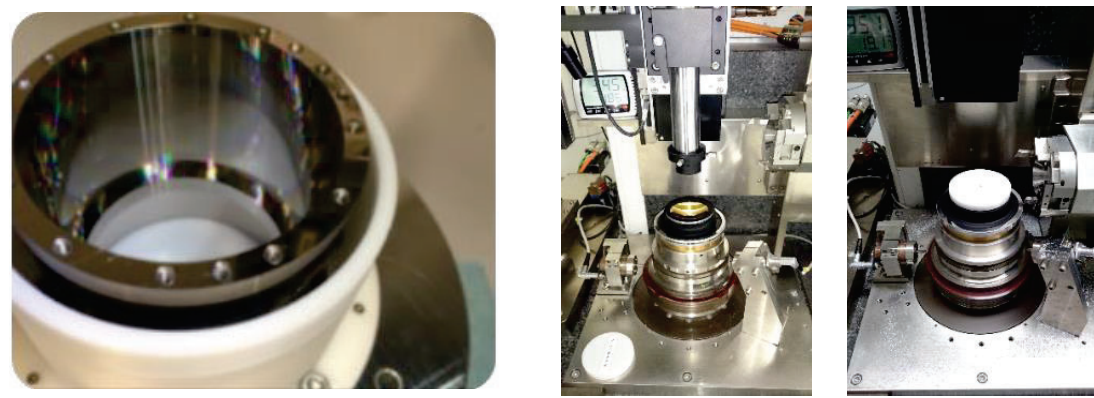

Figure 2-13: Left: Aluminum tubes plated with Ni and diamond turned -almost mirror quality

\subsubsection{Achievement}

The verification of the lens centration after joining the lenses with the lens tube has been performed by us using an OptiCentric measurement system, which allows the determination of the position and tilt of the lens.

As demonstrated in Table 7 due to precision lens centring, only very small centring errors of TOA lenses w.r.t. best fit optical axis occurred which is almost in 1-5 arcsec range identical to the tube axis. The centering errors can be summarized to shifts in the range of $<\approx 1.5 \mu \mathrm{m}$ and tilts in the range of $<\approx 2$ arcsec.

Table 7: Measurement of lens shift and tilt w.r.t. best fit optical axis - results of TOA PFM after lens centering, joining, clamping and settling campaign

\begin{tabular}{|c|c|c|c|c|}
\hline $\begin{array}{c}\text { Optical } \\
\text { element }\end{array}$ & Shift $\mathbf{X}[\boldsymbol{\mu m}]$ & Shift $\mathbf{Y}[\boldsymbol{\mu m}]$ & $\begin{array}{c}\text { Tilt X } \\
{[\operatorname{arcsec}]}\end{array}$ & $\begin{array}{c}\text { Tilt Y } \\
{[\operatorname{arcsec}]}\end{array}$ \\
\hline TES1 & $-0.40 \pm 0.10$ & $1.39 \pm 0.11$ & $1.18 \pm 0.33$ & $-1.01 \pm 0.51$ \\
\hline TES2 & $0.87 \pm 0.14$ & $-1.49 \pm 0.11$ & $-0.71 \pm 0.31$ & $1.61 \pm 0.49$ \\
\hline TES3 & $-0.78 \pm 0.20$ & $0.15 \pm 0.08$ & $-1.26 \pm 0.27$ & $-0.78 \pm 0.53$ \\
\hline TES4 & $0.08 \pm 0.49$ & $0.03 \pm 0.23$ & $0.42 \pm 0.36$ & $1.69 \pm 0.83$ \\
\hline TES5 & $0.99 \pm 0.49$ & $0.12 \pm 0.29$ & $-1.15 \pm 0.33$ & $-0.77 \pm 0.62$ \\
\hline TES6 & $0.15 \pm 0.30$ & $-0.54 \pm 0.25$ & $0.57 \pm 0.65$ & $-0.70 \pm 0.63$ \\
\hline
\end{tabular}


The aimed benefit of this quality is an excellent image quality. For the Telescope the achieved distortion is less than $1 \mu \mathrm{m}$ including a measurement error of $0.3 \mu \mathrm{m}(2 \sigma)$, see Table 8 .

Table 8: Measured PFM telescope distortion (residual to requirement for comparison: $\leq 2.3 \mu \mathrm{m}$ )

\begin{tabular}{|c|c|}
\hline Wavelength [nm] & $\begin{array}{c}\text { Achieved maximum distortion } \\
\text { within FoV }[\mu \mathrm{m}]\end{array}$ \\
\hline 400 & $0.6 \pm 0.3$ \\
\hline 466 & $0.5 \pm 0.3$ \\
\hline 500 & $0.5 \pm 0.3$ \\
\hline 750 & $0.4 \pm 0.3$ \\
\hline 780 & $0.4 \pm 0.3$ \\
\hline
\end{tabular}

\subsection{Lens Clamping}

\subsubsection{Motivation}

The required optical system performance given for example by direct requirements for the stability of the object plane and image plane leads to the need for a very high stability of the lens positions within the lens tubes. This is shown particularly by the fact that only an axial shift for each lens less than $3 \mu \mathrm{m}$ is allowed (refer to chapter 2.1.2 and 2.1.3). Therefore, a clamping system, which suppresses almost any gapping and sliding phenomena due to environmental loads is required.

\subsubsection{Approach of Solution}

To develop such clamping system different aspects, e.g. configuration soft/hard clamping, analytical justification, design, manufacturing and integration have been elaborated. We derived that for the clamping configuration soft clamping via a spring ring is the most robust solution due to the more flat spring rate and better achievable air gap alignment accuracy. In addition, the spring ring allows a good control of the installed preload and minimizes thermal expansion effects.

The next step was to evaluate the required pre-load. Driven by the grip capability to avoid slippage of the optical elements, gapping phenomenon, relaxation effects and setting effects, the minimum pre-load has been defined. Under consideration of the air gaps sensitivity between each lens and strength capability of the stacked parts, the maximum preload could be determined. On the button line, we defined a clamping force of $10000 \mathrm{~N}$ for the TOA, COL and CAM and $7000 \mathrm{~N}$ for NISOA by compressing the respective spring ring of about $100 \mu \mathrm{m}$. To generate this compressing a specified clamping clearance must be determined to take into account the overall stiffness of the clamped system. For this purpose, a special clamping equipment (CGSE) was developed in collaboration with Fraunhofer Institute for Applied Optics and Precision Engineering IOF, which allowed to test and to measure under pre-load the complete assay /6/.

After the pre-load definition, including margins against failure modes the potential pre-off-set for the as-designed lens positions was defined to ensure the necessary air gaps. A variety of finite element models (FEM) with different mounting conditions of the lens stacks, e.g. multipoint constraint equations (MPC) or GAP elements to simulate contact, were used for this purpose (see Figure 2-14 left). In addition, the FEMs were used to compute the lens shifts for all possible clamping conditions (e.g. after assembly, after settling, after settling and relaxation) to ensure the required performance. 

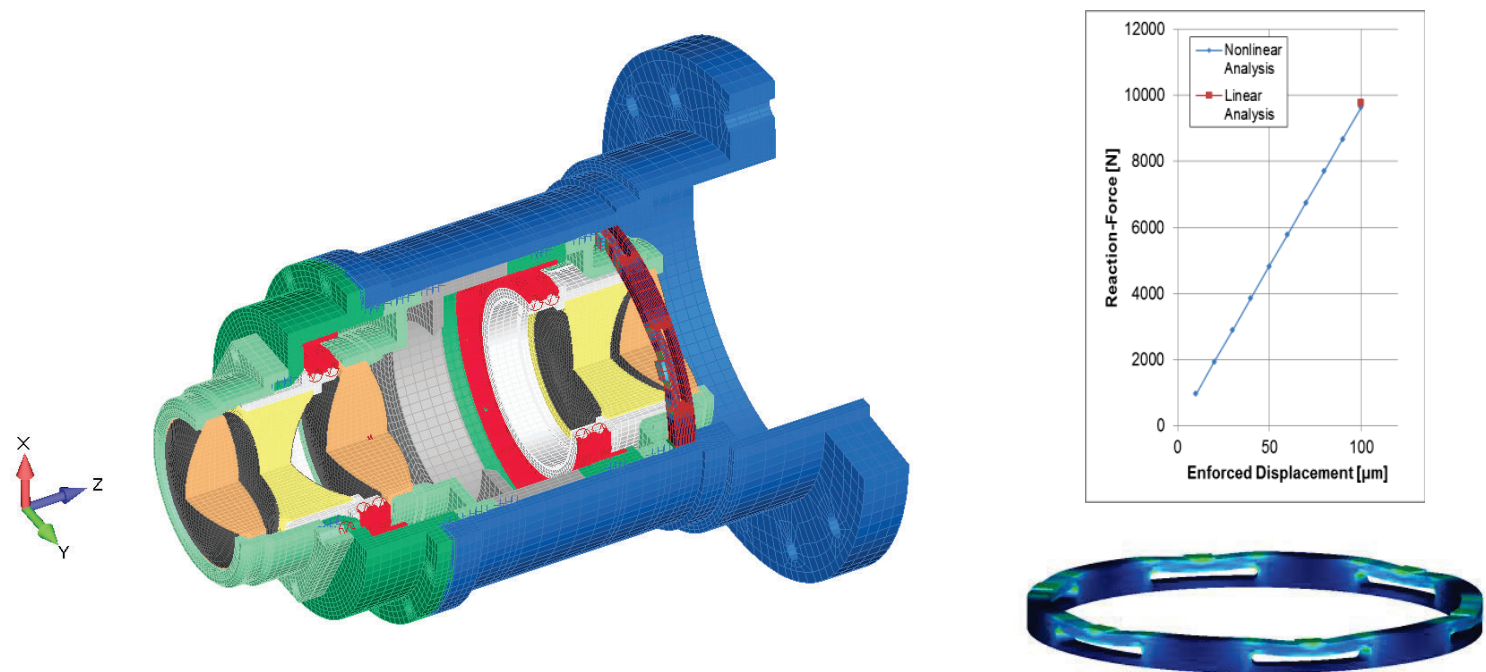

Figure 2-14: FEM for calculation of the pre-off-set of the lens position. Left: FEM of Collimator to simulate the clamping process (COL). Right: Finite element analysis (FEA) of spring ring stiffness for COL

\subsubsection{Design}

The spring ring made of high strength stainless steel consists of six uniformly distributed spring elements generating approximately $10000 \mathrm{~N}$ clamping force by $100 \mu \mathrm{m}$ compression in assembled state. The titanium pressure ring (yellow ring shown in Figure 2-15) reduces the surface pressure on the subsequent aluminum parts and is used to prevent contact corrosion.

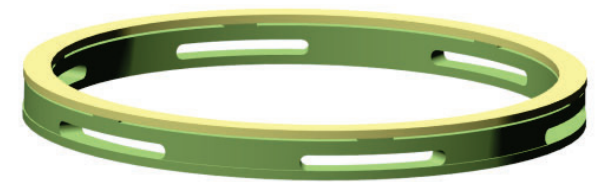

Figure 2-15: Spring ring with pressure ring (yellow)

The integration of the respective spring ring into the design of the four optical subassemblies is shown in Figure 2-16. It should be mentioned that the preferred configuration could be implemented at three assemblies (TOA, NISOA and CAM) where the spring ring is located at the end of the tube. In this way the compression of the spring ring is decoupled from the lens stack movement. Only for the configuration of the Collimator (COL) the spring ring is positioned at the end stop of the lens stack. Hence, the compression of the spring ring is produced by the movement of the complete lens stack. Since the relative position of the lens stack within the tube determines the final object plane position of the complete USA, this configuration requires a very good prediction of the clamping process to define the needed pre-offset of the COL5 lens located next to the CAM interface (I/F) respectively to CAM1 lens. 
TOA of TA

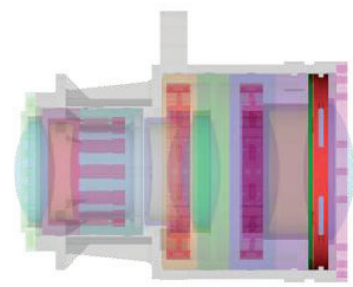

COL of USA

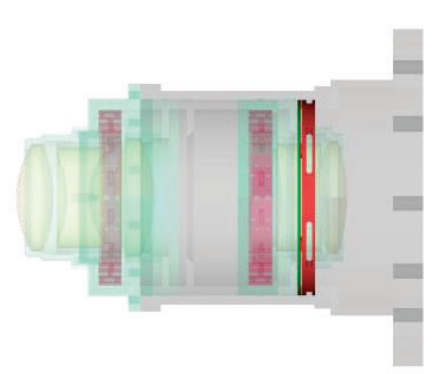

NISOA of NSA

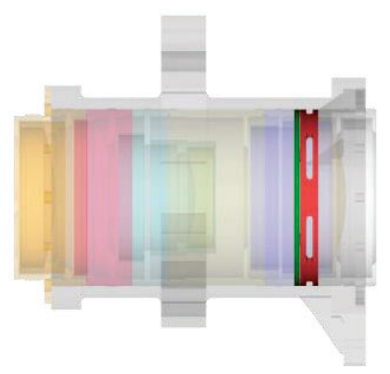

CAM of USA

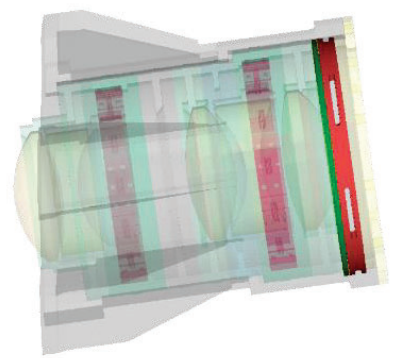

Figure 2-16: Integration of spring ring into the design of the four optical subassemblies

\subsubsection{Achievement}

The final clamping status is verified again with our OptiCentric measurement setup. In Figure 2-17 image of the COL (collimator lens) of the UV-VIS spectrometer on the OptiCentric measurement setup is provided.

To verify that the clamping hast been successful we performed vibration and thermal settling on the optical system and performed OptiCentric measurements before the campaign, after the thermal and after the vibration settling. The measured data for the change in position and tilt for each lens of the COL are shown in Figure 2-17 and summarized in Table 9.

Looking at the air distances between the lenses summarized in Table 9, one can see that the settling campaign changes these air distances only up to $3 \mu \mathrm{m}$.

In conclusion, we verified that we have a very robust design.
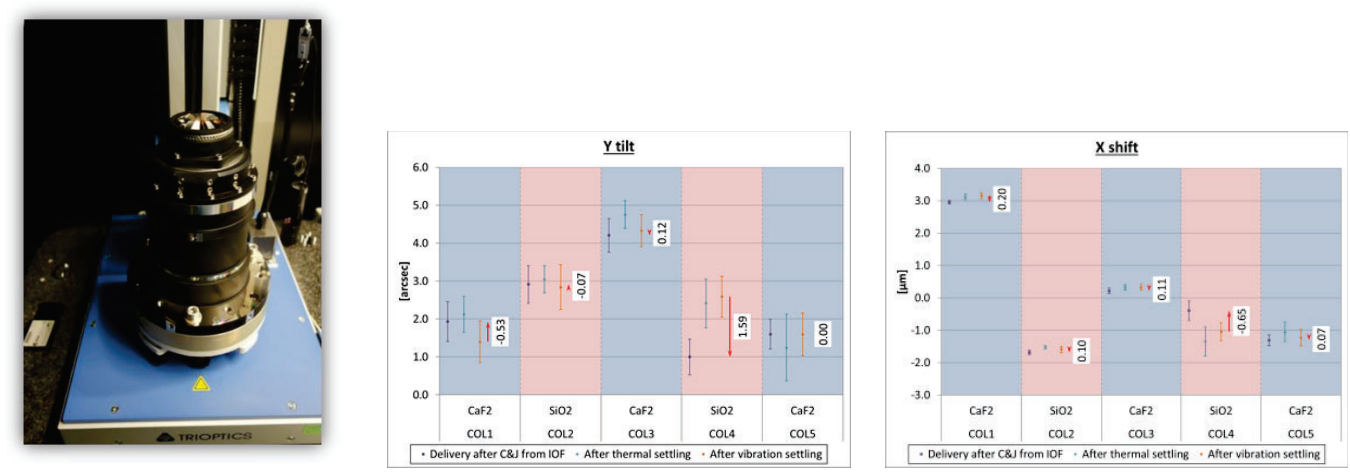

Figure 2-17: Left: COL (collimator lens) of the UV-VIS spectrometer on the OptiCentric measurement setup Right: Tilt and Shift one-dimensional of the lens singlets inside the COL optic before and after environmental loads 
Table 9: Tilt and Shift of the lens singlets inside the COL optic before and after environmental loads

\subsection{Stray Light}

\begin{tabular}{|c|c|c|}
\hline Air distance & $\begin{array}{c}\text { Thickness before } \\
\text { settling [mm] }\end{array}$ & $\begin{array}{c}\text { Maximum difference } \\
\text { before settling/after TV } \\
\text { settling/after vibration } \\
\text { settling }[\mu \mathrm{m}]\end{array}$ \\
\hline COL1/COL2 & $8.1976 \pm 0.0002$ & $2.2 \pm 0.2$ \\
\hline COL2/COL3 & $14.1597 \pm 0.0004$ & $3.0 \pm 0.5$ \\
\hline COL3/COL4 & $74.9942 \pm 0.0003$ & $2.6 \pm 0.4$ \\
\hline COL4/COL5 & $3.6911 \pm 0.0003$ & $2.3 \pm 0.3$ \\
\hline
\end{tabular}

\subsubsection{Motivation}

The high-end optical performance requires to tackle stray light optimization measures very early on in the project. As the total integrated scatter is proportional to $1 / \lambda^{2}$, in-field stray light is mostly generated in the UV wavelength range of the instrument. The fact that the light in the UV-VIS beam path passes in total 37 surfaces shows the potential to generate stray light within the instrument. Despite the common understanding that UV spectral range of imaging path is essential more sensitive a UV-VIS spectrometer needs high control also of the VIS spectral part due to higher signal strength (Sun spectra see Figure 2-18) as well as the reduced QE in the UV range to avoid disturbing crosstalk.

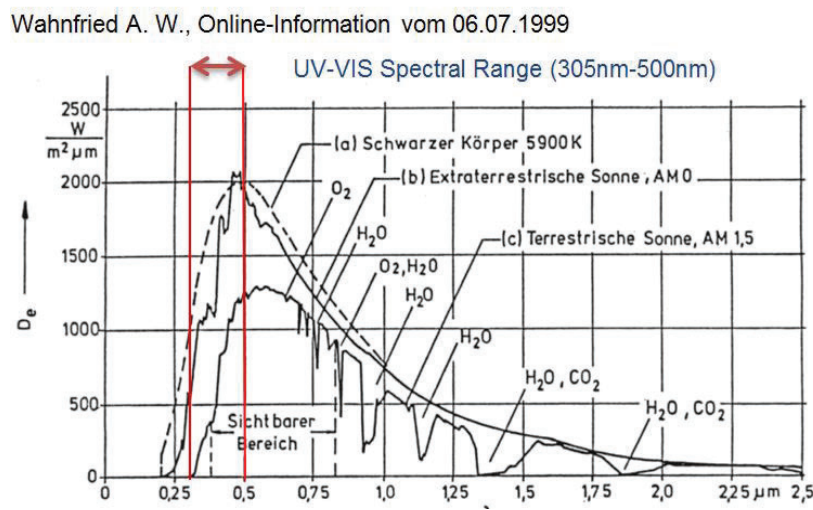

Figure 2-18: Sun spectrum vs. UV-VIS used spectral range

Despite that, we should note that stray light is an issue for the whole wavelength range of the instrument and needs to considered throughout the design.

\subsubsection{Approach of Solution and Design}

Starting with the PDR design dedicated stray light analysis were obligatory produced with focus of dedicated stray light baffling, blocking critical paths. Especially for the spectrometer the "zero" order of diffraction from the grating elements must be controlled.

Additionally to the proper definition of blades JOP have procured high end lens polishing quality for spherical as well as aspherical surfaces, mastered by Asphericon $\mathrm{GmbH}$. The produced surface quality w.r.t. roughness was almost less than $0.5 \mathrm{~nm}$ RMS $(1 \mu \mathrm{m}-1 \mathrm{~mm})$.

Furthermore, we perform detailed defect inspections of the optics throughout the full manufacturing and alignment steps additionally to a full defect surface mapping that is generated after the high-performance AR coating.

The third stray light counter measure is to use black coatings on all stray light relevant parts. Even the lens rim is coated black and the glue used has been self-blackened by us. 
Finally, we implemented a very strict cleanliness control covering all stages of the manufacturing process after the joining of the lenses and the lens tube. As a result we achieved on the optical surfaces the cleanliness values stated here which are compliant with the requirements.

Table 10: Overview over applied stray light reduction measures

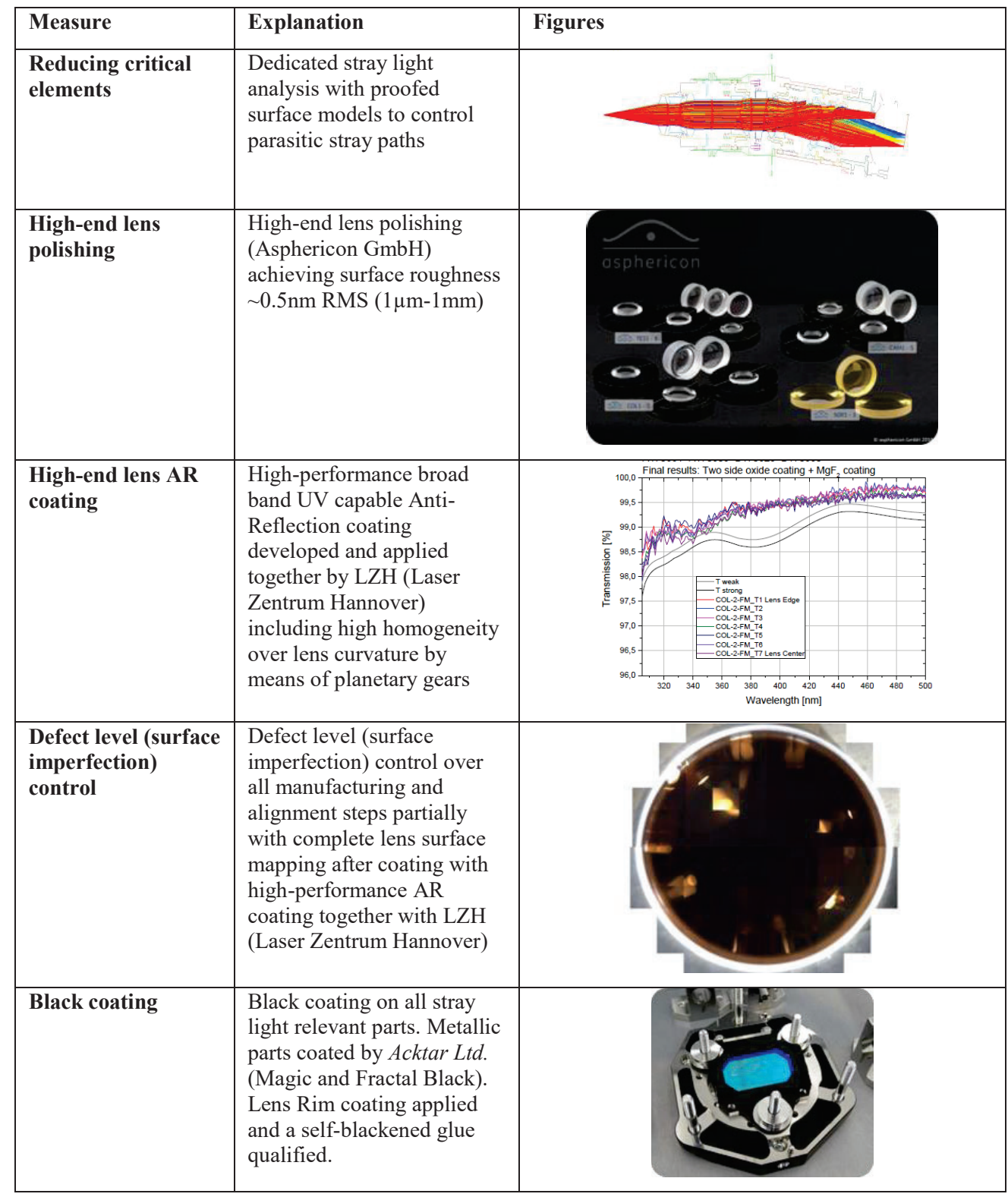




\begin{tabular}{|l|l|}
\hline $\begin{array}{l}\text { Cleanliness control } \\
\text { and Bakeout }\end{array}$ & $\begin{array}{l}\text { Cleanliness control of parts } \\
\text { over all stages results in } \\
\text { optical surface quality: }<40 \\
\text { ppm PAC and }<88 \mathrm{ng} / \mathrm{cm}^{2} \\
\text { MOC contamination based } \\
\text { on extended bake-out } \\
\text { program and UV inspection } \\
\text { strategy on all subsystems } \\
\text { and system level }\end{array}$ \\
\hline
\end{tabular}

\subsubsection{Achievement}

Stray light characterization for all three PFM COAs were successful completed. For stray light characterization tests the performance OGSE was used to determine stray and ghost signal around in-field and out-of-field or out-of-band illumination. For Telescope Assembly (Telescope + Slits) the slit was re-imaged. Illumination, integration time and repetition were optimized to derive a requested Signal-to-Noise ratio called detection chain limited accuracy (DCLA) of DCLA in-field $<10^{-5}$ and of DCLA out-of-field $<10^{-7}$ for the telescope only.

Overall, the measurements showed no signs of stray light, which leads us to the conclusion that we indeed developed and have realized a straylight optimized design. In the derived DCLA no stray- or ghost signals could be identified.
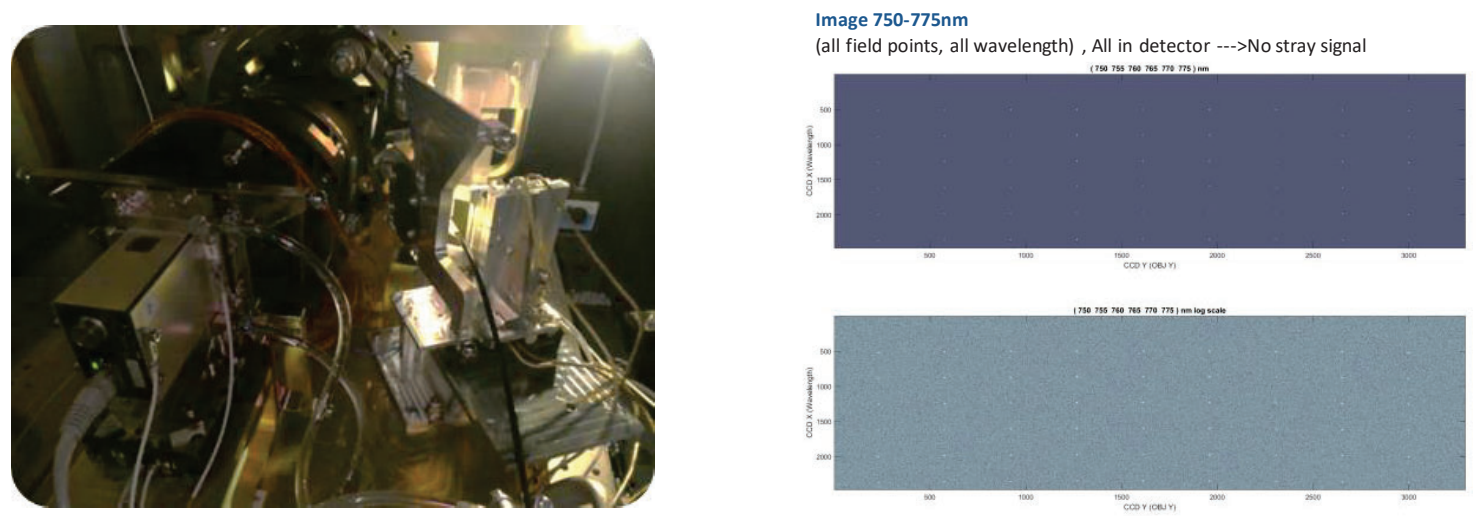

Figure 2-19: Left: NSA on the optical performance measurement setup used also for stray light verification. Right: Summary image of detector with vertical discrete wavelength from 745 to $780 \mathrm{~nm}$ and 9 field points over the full slit length in linear and log plot.

\section{SUMMARY \& CONCLUSION}

The very demanding performance requirements led to an instrument design, which sets the demands on manufacturing and alignment quality to a new level. To achieve the optical quality, the lens mounting was optimized to utilize technologies, which provides an undistorted, highly centered and stable lens position capable for extended bake-outs to reduce potential contaminations in the UV wavelength range. Furthermore, a completely new gluing and clamping technology has been established and the centering was optimized almost to the peak of precision [6]. To realize the instruments performance over the complete specified thermal range Jena-Optronik developed a unique passive thermal focus compensation for the lens optics, which acts like a passive auto-focus system w.r.t. thermal changes. All challenges reported in this paper were finally successfully tackled by design, breadboarding, enhanced manufacturing and verification of the Flight H/W. Early 2020 we successfully finished our verification campaign for all three PFM optical assemblies and proudly handed them over to our customer. 

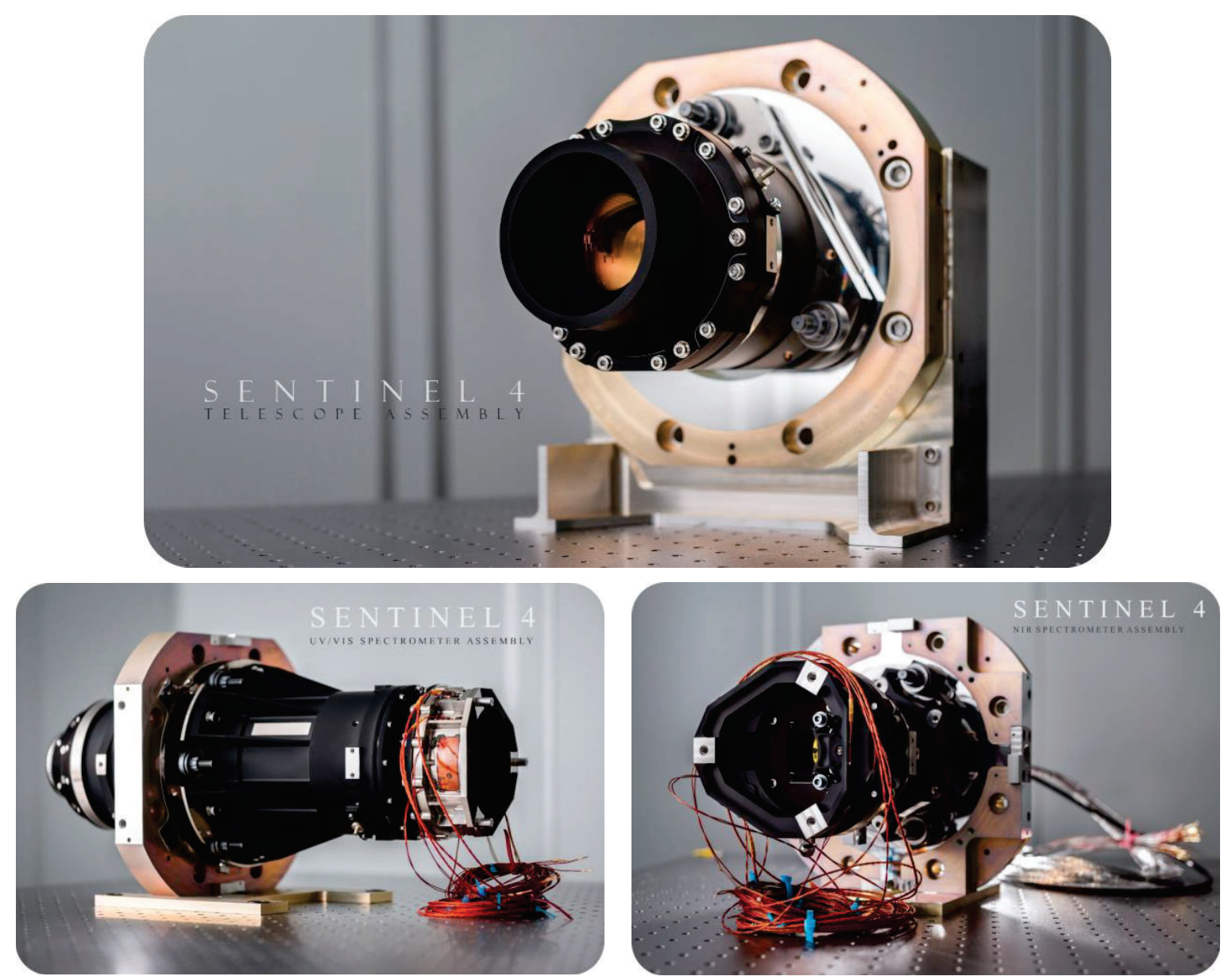

Figure 3-1: Images of the PFM combined optical assemblies for the Sentinel-4 UVN Instrument after the end of the verification test campaign. Top: Telescope Assembly; bottom left: UV/VIS Spectrometer Assembly; bottom right: NIR Spectrometer Assembly

\section{ACKNOWLEDGEMENT}

The described work has been produced with the financial assistance of the European Union. The views expressed herein can in no way be taken to reflect the official opinion of the European Union and/or ESA.

JOP would like to acknowledge the extraordinary support by the customer Airbus Ottobrunn (Airbus Defence and Space), especially by O. Seger, G. Kling and Ch. Ehrhart.

Essential contributions to this successful and outstanding project were also provided by several suppliers and subcontractors: (Lens manufacturing: S. Kiontke and the colleges from Asphericon; AR coating: T. Böntgen and the colleges from Laser Zentrum Hannover; Centering and BSA Slits Assemblies: A. Gebhardt, M. Mohaupt and the colleges from Fraunhofer IOF; Grism: P. Triebel and the colleges from Carl Zeiss Jena GmbH; Dichroic: A. Hervy and the colleges from Safran Reosc). The success also based on outstanding handcraft work done by the JOP production department special by U. Werner, M. Rosemann under the lead of St. Krüger. 


\section{REFERENCES}

[1] ESA - Sentinel-4 Mission Introduction, https://sentinels.copernicus.eu/web/sentinel/missions/sentinel-4 (08.02.2021)

[2] Stark, H., Moeller, H., Courreges-Lacoste, G., Koopman, R., Mezzasoma, S., Veihelmann, B., "The Sentinel-4 mission and its implementation", ESA Living Planet Symposium, (2013).

[3] Courrèges-Lacoste, G., Sallusti, M., Gulde, S., Bulsa, G., Bagnasco, G., Kolm, M., Smith, D., Maurer, R., "Knowing what we breathe: Sentinel 4: a geostationary imaging UVN spectrometer for air quality monitoring", Proc. SPIE 10562, International Conference on Space Optics - ICSO 2016, 105621J (2017).

[4] S. Riedl, M. Harlander, C. Schlosser, M. Kolm, R. Maurer, G. Bazalgette Courrèges-Lacoste, C. Pachot, B. Ahlers, S. Grabarnik, L. Gambicorti, M. Sallusti, G. Bulsa, G. Bagnasco, "Sentinel 4 UVN: a geostationary imaging UVN spectrometer for air quality monitoring: performance, measurement modes and model philosophy," Proc. SPIE 11180, International Conference on Space Optics — ICSO 2018, 1118005 (2019)

[5] Airbus - The driving force for Copernicus, https://www.airbus.com/space/earth-observation/copernicus.html (08.02.2021)

[6] Andreas Gebhardt, Erik Schmidt, Torsten Hertel, Steffen Kirschstein, Eyk Gebhardt, Thomas Rendel, Ute Gawronski, Vinzenz Wand, "Alignment Turning and Assembly of the Sentinel 4 Optical Modules," ICSO $2020,(20.02 .2021)$ 